\title{
Assessment and Evaluation Practices in Engineering Education: A Global Perspective
}

\author{
N. P. Subheesh, Satya Sundar Sethy \\ Department of Humanities \& Social Sciences \\ Indian Institute of Technology Madras \\ Chennai, India \\ npsubheesh@gmail.com
}

\begin{abstract}
Assessment' and 'evaluation' are the integral parts of the engineering curriculum. These components have direct relevance to quality assurance in engineering education. Literature suggests that better assessment and evaluation practices require certain knowledge and skills about types and methods of assessment and evaluation. It is found that most of the engineering faculty members do not have concrete knowledge about 'assessment' and 'evaluation' types and methods. Further, it is argued that engineering educators are not well aware of 'feedback comments' that are associated with assessment practices. Comments on students' performances are essential because it helps them to know their strengths and weaknesses of a course. In this background, the paper critically analyses assessment and evaluation practices in engineering education setup across the globe. In particular, it discusses the challenges faced by engineering faculty members while assessing students' performances. Finally, the paper offers suggestions to improve assessment and evaluation practices so that students doing engineering programs will be largely benefited.
\end{abstract}

Keywords- Engineering Education; Assessment; Evaluation; Feedback Comments; Quality Assurance in Engineering Education

\section{INTRODUCTION}

'Assessment' in higher education context refers to judging students' performance by awarding them score/mark about the quality and extent of their achievement and providing qualitative feedback [1]. It is an essential component of the teaching-learning process that influences students on the one hand and course teachers on the other hand. It motivates students to learn subject contents and assists them to enhance their learning. It guides them to identify strengths and weaknesses of their learning. It also gives an opportunity to students to overcome weaknesses of their learning. It guides course teachers to evaluate their teaching performance with reference to the courses that they offered to students. While assessing students' performances, they receive feedback on the instructional design and effectiveness of the courses. They identify the reasons for students' good and bad performance(s) of the course. By using the assessment results, course teachers check whether students have achieved the learning objectives of the course or not. Assessment, therefore, stimulates learning in multiple ways. In short, it encourages and motivates students to learn the subject contents, to diagnose their strengths and weaknesses of a course, supplies information to plan what they will do next.

In an engineering education setting, which is a part of higher education, assessment plays a vital role to diagnose students' knowledge and skills in the engineering courses. Engineering students require certain skills that would not be assessed effectively by traditional assessment practices [2]. According to Suskie [3], in traditional assessment practices, the focus is on reproducing the memorised knowledge. Further, assessment is planned and executed without setting the instructional objectives. One tool and one assessment strategy are followed across the courses of a programme. Assessments are based on purely course teachers' expectations from students. Further, assessment is treated as merely a practice where course teachers often give quantitative feedback (e.g. number) and seldom qualitative feedback. This often leads to poor quality of learning for students. In contrast to traditional assessment practices, 'authentic' assessment practices are developed from research and best practices on teaching and assessment methodologies [4], [5]. Authentic assessment practices are carefully aligned with learning objectives. These focus on the enhancement of students' performance, skill, and creativity. Design and implementation of such assessment methods are regarded as professional tasks [6] in which most of the engineering educators lack expertise.

In higher education, the term 'evaluation' refers to the use of quantitative evidence/data [7]. It does not include the qualitative feedback component. Thus, evaluation is purely quantitative in nature. In contrast to evaluation, 'feedback' is an integral part of the assessment. The notion of assessment necessarily includes qualitative feedback. Hence, assessment can be regarded as 'qualitative'. The feedback associated with assessment is used to improve students' learning and course teachers' teaching.

\section{CRITICAL REVIEW OF TyPES AND METHODS OF ASSESSMENT AND EVALUATION}

Formative assessment and summative assessment are regarded as the two 'types' of assessments whereas criterionreferenced assessment and norm-referenced assessments are considered as assessment 'methods'. 'Evaluation' also has a similar classification. 


\section{A. Formative Assessment}

Formative assessment is defined as the task or activity which provides feedback for students about their learning [8] It does not carry a quantitative score/mark, which is associated with a summative judgment. Instead, it contains a qualitative feedback component (only), which is used by course teachers and learners to improve the ongoing teaching-learning process. In this sense, formative assessment is conversational in intent, which tries to help the student in recognising the path by which his/her performance can be better. Activities relating to formative assessment are often entangled with instructional objectives. Formative assessment can be used to assess learners for modifying instructional objectives and correcting further learning as in a feedback loop. This is made through ongoing and timely qualitative feedback processes until the achievement of all instructional objectives for better learning [9]. Thus, formative assessment is described in the educational literature as 'assessment for learning'.

\section{B. Summative Assessment}

Irons [8] defines summative assessment as an activity that results in a mark or grade which is subsequently used as a judgment on student performance. Here students' receive the 'final language' in the form of mark/score. Summative assessment marks are used to classify students in a class at the end of a course or a programme. Its function is to measure achievement of instructional objectives and report the same to students, parents, and other stakeholders. Summative assessment is stated in literature as 'assessment of learning'. This 'assessment of learning' generally occurs at the end of a semester in a course. Summative assessment often includes awarding a final Cumulative Grade Point Average (CGPA) or marks. Hence, it can be used for certifying the required levels of competency achieved by students.

The difference between formative and summative assessment can be described with an analogy. When a cook tastes the soup, it is formative assessment and when a guest tastes the soup, it is a summative assessment. To explain, when the cook tastes the soup by himself he can improve it and make it better before serving to the guest, but when the guest tastes the soup, even if it is not good, it does not get a chance for improvement.

\section{Criterion-Referenced Assessment}

In the criterion-referenced assessment, course teacher cum assessor's judgments on students' performances are made based on the achievements of course objectives. Thus, in criterion-referenced assessment, it is theoretically possible that each and every student belonging to a course could achieve all the learning outcomes and end up with a higher grade, let's say ' $S$ ' grade. It justifies the relation between the course objectives achievements and the scores awarded [10]. Criterion-referenced assessment is most often, but not always, conveys students' achievements and earned competency in a course. In the criterion-referenced assessment, what extent a student achieves the intended learning outcomes of a course is judged [9]. Biggs [11] enunciates that in criterion-referenced assessment, a correlation exists among course objectives, teaching and learning activities, and assessment tasks.

\section{Norm-Referenced Assessment}

In a norm-referenced assessment, a course teacher judges a student's achievements by comparing with his/her classmates' achievements on an assignment [1]. Even without achieving all the course objectives, a student may stand first in a class. Norm-referenced assessment is colloquially known as 'grading on the curve'. It is so because; grade sheet of a student is often designed through a 'bell-curve'. It is observed that in norm-referenced assessment, course teachers push some of the students to higher grades than they deserve or pull some students from their deserving grades to design the 'bellcurve'. Thus, mark-sheet designed through such a curve is always treated as relativistic [10]. While comparing a student's achievements with his/her classmates on an assignment task, course teacher's subjective and biased notions on assessment may not be ruled out. Thus, normreferenced assessment does not communicate students' real achievements of a course and thereby misguides the students.

\section{E. The Distinction between Assessment and Evaluation}

As enunciated earlier, assessment can be regarded as the process of collecting data, reviewing it and using the information for improving learning by providing qualitative feedback [3]. On the other hand, evaluation is the process of making judgments about the teaching-learning system based on predefined criteria and standards. In this sense, assessment is to improve the quality and evaluation is to judge the quality. Assessment is diagnostic and process-oriented whereas evaluation is judgemental and product-oriented.

Evaluation is the final step that is used to gauge the quality of an instructional system. It focuses on grading and certification. Evaluation certifies students where they stand in a course in a programme. The information on how much they have achieved subject knowledge and whether they have attained the required skills of a profession can be obtained through certification. Certification can also be done in conformity with the regulations of an external professional body [9]. In this regard, it supplies information to the various stakeholders associated with engineering education. Stakeholders may use the evaluation results for specific purposes such as employment short-listing. This underlines the necessity of evaluation in addition to formative and summative assessments.

\section{F. Evaluation Types}

Evaluation, which is purely quantitative in nature, can also be classified as formative and summative. As mentioned earlier, the significant difference is 'evaluation' does not contain any (qualitative) feedback, in contrast to assessment. It involves assigning marks/scores only. This difference can be pinpointed with examples of Formative Assessment (FA), Summative Assessment (SA), Formative Evaluation (FE), and Summative Evaluation (SE). In an engineering course, if qualitative feedback is only provided to students' responses, then it is judged as FA. Nevertheless, if only marks/grades assign to the students' responses, then it is treated as FE. When course teachers provide qualitative feedback along with marks/scores on students' responses, it can be treated as SA. Quizzes (Quiz 1, 2, etc.) having both feedbacks (to perform 
better) as well as marks/scores is an example of SA. Quiz marks will contribute to final grading. Summative Evaluation (SE) is the final grade/mark students receive at the end of a course. Normally at the semester/year end, students are awarded a final grade/mark without any qualitative feedback (from the course teacher). This can be regarded as an example of SE.

\section{SignifiCANCE OF FEEDBACK AND FEEDBACK COMMENTS}

The expressions 'assessment' and 'feedback' are invariably and indubitably related to each other. Feedback is the teacher's response to student's performance. Assessing students' performances and providing feedback on the performance is a professional approach to assessment practices. The rationale for providing feedback is to help students to use feedback for the enhancement of their learning. An effective assessment thus offers feedback on students' performances. Assessment feedback guides students about where and how they ought to be able to go next.

Irons defines feedback as "any information, process or activity which affords or accelerates learning, whether enabling students to achieve higher quality learning outcomes than they might otherwise have attained or by enabling them to attain these outcomes more rapidly" [8]. Black and Wiliam identify feedback as a key component of formative assessment [12]. Pellegrino suggests that learning is a process of continuously modifying knowledge and skills and that feedback is essential to guide and redirect student's thinking [13].

According to Yorke, "Academic professionals should begin by commenting on strengths of students' performance, moves on to discuss weaknesses, and rounds the comments off with encouragement for the future" [9]. Broadly, there are five types of comments assessors should understand and use the feedback practices. It is endorsed by Gibbs [14], Nicol and Milligan [15].

- Comments on the content of student's response

- Comments designed to enhance student's skills

- Comments that encourage further learning

- Motivational comments on students' performance

- De-motivational comments on students' responses

\section{ENGINEERING EDUCATION AND ASSESSMENT PRACTICES}

Integrating a process of good assessment practice into academic programmes has to be a major goal of every engineering educational institution [16]. McDowell, White and Davis [17] state that engineering departments are often criticised by their students and by external quality reviewers, for paying insufficient attention to the effective implementation of good assessment practices. Christoforidou, Kyriakides, Antoniou, and Creemers enunciate that researchers need to identify and tackle such difficulties in effective implementation of efficient assessments [18]. In Shaeiwitz view [19], to implement a good assessment plan, a paradigm shift in engineering faculty culture is needed so that faculty members will communicate more about expectations from course content and student learning.

Design, development and implementation of assessment practices are challenging activities as assessment itself evolves time to time along with the course curriculum, instructional design and course objectives. Since engineering faculty members hardly have had any formal training to learn how to design a course, they are prone to commit an error while designing instruction of a course. Further, they are not able to formulate effective assessment strategies and assessment tools of a course. According to Felder and Silverman, "The infusion of accepted principles and practices of educational assessment are having a significant impact on the development of engineering curricula and the evaluation in terms of student performance" [20].

In this context, Palmer enunciates that "engineering educators should seek assistance from experts, where required, to help in the development of appropriate student assessment" [21]. He further points out that the pedagogies and measuring techniques appropriate to the broader graduate attributes are not widely known in engineering, and it will take the time to acquire experience in them. Formulating measurable learning outcomes and assessing students' performances are sophisticated activities with which most engineering educators have had little or no experience [22].

Nonetheless, for an engineering faculty member, it is not so easy to find out an educational expert who can help him in developing better assessment practices. Practical guidelines on effective assessment design in engineering courses are also not readily available in engineering departments [21]. This is a global scenario pointing to the need of more research study in the area of student assessment and evaluation practices in engineering education. It would be better if we can train and develop such 'assessment expert' within each engineering departments so that they can help other faculty members. It can be done in collaboration with other departments like education and social sciences. Existing educational theories can then be tailor-made for engineering education to improve both students learning and the quality of teaching.

From the global perspective, it is true that engineering faculty members need not go through teacher training, orientation, and certification programmes to join in engineering teaching. This may result in them in difficulties to develop better assessment tools, techniques of a course and thereby practices to assess students' learning. Any sort of wrong assessment practice misguides students about their learning and provides wrong information about where they stand in a course. It further gives a wrong impression to the stakeholders about the achievements and skills of engineering graduates. This phenomenon does not help in achieving the objectives of engineering education.

In addition, to develop the required skills of engineering professionals, new forms of learning are introduced, such as teamwork based collaborative learning, problem-based learning, active learning, etc. The practices for assessing students' responses are also constantly changing. To put up with these ever-changing demands of assessment practices 
course instructors need to learn the multiple assessment practices in engineering education.

Another issue, which can be traced from literature, most of the engineering institutions across the globe are using normbased assessment practices those are treated as subjective [1], [10], [23]. The assessors are making judgments on students' performance based on their gut feelings, previous experiences and existing conventions. As a result, the stakeholders may not know what the level of achievement of a student is, in a particular course.

\section{A. Assessment and Quality Assurance}

According to Yorke, assessment plays a pivotal role to ascertain quality in HE settings [9]. Quality can't be reduced to merely a set of quantified learning outcomes [24]. So improving the quality of learning for students is not just ensuring achievement of learning outcomes by grading at the end of the course. However, if integrity in grading were achieved tolerably well, it would be possible to evaluate the quality of teaching and learning [25]. Therefore, engineering education settings, assessment does not only help students for the growth of their learning but also monitor and continuously assist in improving the quality of programmes. Sadler further enunciates that through better assessment and grading practices quality assurance in engineering education can be ascertained [25].

\section{DeVelopment of An EFFeCtive Assessment Practice}

Establishing clear as well as measurable instructional objectives is the first step in the development of an authentic student assessment [26]. In this regard, teacher training on basic instructional system design emphasising Bloom's taxonomy [27] would be helpful to establish and classify instructional objectives. Next phase is the design and implementation of regular formative assessment (and qualitative feedback) for the improvement of learning. These ongoing, continuous assessment tasks should be carefully aligned with the predefined instructional objectives.

In the real contexts of engineering education, information and communication technology (ICT) options such as webbased assessment tools shall be considered to enhance assessment effectiveness [28]. For instance, a two-level objective test based on students' misconceptions in an engineering course can be implemented [29]. Based on the answers clicked by the student in the two levels of linked questions, online qualitative feedback can be provided. If properly designed, this feedback can pinpoint the misconception associated with student's conceptual understanding related to each of the instructional objectives. It can be done on a regular basis for the continuous improvement of learning. Such a web-based design can be used and reused for practical situations like those that large numbers of students are enrolled in a course. In addition, employing a combination of criterion-referenced assessment and normreferenced assessment by taking positive aspects from both would also be beneficial.

\section{SugGeSTiONS TO IMPROVE ASSESSMENT AND EVALUATION}

- Assessment and evaluation practices have to be carefully aligned with instructional objectives of the course. Establishing clear, measurable instructional objectives is a prerequisite for the same.

- The assessment 'for' learning - formative assessment (and hence qualitative feedback) has to be given much more priority than assessment 'of' learning summative assessment.

- An optimal mix of criterion-referenced assessment and norm-referenced assessment can be adapted. Course teacher's subjective and biased notions on assessment can be ruled out by giving more preference to criterion-referenced assessment.

- Faculty members need to learn the multiple assessment and evaluation practices with regard to new forms of learning such as teamwork based collaborative learning, problem-based learning, active learning, etc.

- Engineering faculty members have to seek assistance from experts, where required, to get help in the development of authentic student assessment. Appropriate teacher training has to be offered to engineering faculty members across the globe, particularly on assessment practices. A comprehensive training on instructional design and educational theories leading to authentic assessment and evaluation practices can be quite useful.

\section{REFERENCES}

[1] S. S. Sethy, "Students' expectations about their grades versus course expectations from them," Int. J. Qual. Assur. Eng. Technol. Educ., vol. 2 , no. 4, pp. 1-15, 2012

[2] O. Rompelman, "Assessment of student learning: evolution of objectives in engineering education and the consequences for assessment," Eur. J. Eng. Educ., vol. 25, no. 4, pp. 339-350, 2000.

[3] L. Suskie, Assessing Student Learning: A Common Sense Guide. San Francisco, CA: John Wiley \& Sons, 2010.

[4] A. L. Guzzomi, S. A. Male, and K. Miller, "Students' responses to authentic assessment designed to develop commitment to performing at their best," Eur. J. Eng. Educ., vol. 3797, no. 1, pp. 1-22, 2015.

[5] R. Olfos and H. Zulantay, "Reliability and validity of authentic assessment in a web-based course," Educ. Technol. Soc., vol. 10, no. 4, pp. 156-173, 2007.

[6] J. Baggini, "What professionalism means for teachers today.," Educ. Rev., vol. 18, no. 2, pp. 10-21, 2005.

[7] M. Scriven, "Duties of the teacher," J. Pers. Eval. Educ., vol. 8, no. 1, pp. 151-184, 1994.

[8] A. Irons, Enhancing Learning through Formative Assessment and Feedback. New York: Routledge, 2008.

[9] M. Yorke, Grading Student Achievement in Higher Education. London: Routledge, 2008.

[10] D. R. Sadler, "Interpretations of criteria-based assessment and grading in higher education," Assess. Eval. High. Educ., vol. 30, no. 2, pp. 175 194, 2005.

[11] J. Biggs, Teaching for Quality Learning at University. Buckingham: SRHE/Open University Press, 1999.

[12] P. Black and D. Wiliam, "Developing the theory of formative assessment," Educ. Assessment, Eval. Account., vol. 21, no. 1, pp. 5-31, 2009. 
[13] J. W. Pellegrino, "Assessment of science learning: living in interesting times,” J. Res. Sci. Teach., vol. 49, no. 6, pp. 831-841, 2012.

[14] G. Gibbs and C. Simpson, "Conditions under which assessment supports students' learning," Learn. Teach. High. Educ., vol. 1, no. 1, pp. 3-31, 2004.

[15] D. J. Nicol and C. Milligan, "Rethinking technology-supported assessment practices in relation to the seven principles of good feedback practice," in Innovative Assessment in Higher Education, C. Bryan and K. Clegg, Eds. London: Routledge, 2006, pp. 64-77.

[16] J. McGourty, "Four strategies to integrate assessment into the engineering educational environment," J. Eng. Educ., vol. 88, no. 4, pp. 391-395, 1999.

[17] L. McDowell, S. White, and H. C. Davis, "Changing assessment practice in engineering: how can understanding lecturer perspectives help?," Eur. J. Eng. Educ., vol. 29, no. 2, pp. 173-181, 2004.

[18] M. Christoforidou, L. Kyriakides, P. Antoniou, and B. P. M. Creemers, "Searching for stages of teacher's skills in assessment," Stud. Educ. Eval., vol. 40, pp. 1-11, 2014.

[19] J. A. Shaeiwitz, "Outcomes assessment in engineering education," J. Eng. Educ., vol. 85, no. 3, pp. 239-246, 1996.

[20] R. M. Felder and L. K. Silverman, "Learning and teaching styles in engineering education," Eng. Educ., vol. 78, no. 7, pp. 674-681, 1988.
[21] S. Palmer, "Authenticity in assessment: reflecting undergraduate study and professional practice," Eur. J. Eng. Educ., vol. 29, no. 2, pp. 193202, 2004.

[22] H. Vos, "How to assess for improvement of learning," Eur. J. Eng. Educ., vol. 25, no. 3, pp. 227-233, 2000.

[23] D. Betebenner, "Norm and criterion-referenced student growth," Educ. Meas. Issues Pract., vol. 28, no. 4, pp. 42-51, 2009.

[24] C. Bryan and K. Clegg, Eds., Innovative Assessment in Higher Education. London: Routledge, 2006.

[25] R. D. Sadler, "Assessment, evaluation and quality assurance: implications for integrity in reporting academic achievement in higher education," Educ. Inq., vol. 3, no. 2, pp. 201-216, 2012.

[26] B. M. Olds, B. M. Moskal, and R. L. Miller, "Assessment in engineering education: evolution, approaches and future collaborations," J. Eng. Educ., vol. 94, no. 1, pp. 13-25, 2005.

[27] D. D. R. Krathwohl, "A revision of Bloom's taxonomy: an overview," Theory Pract., vol. 41, no. 4, pp. 212-218, 2002.

[28] E. Guzman and R. Conejo, "Self-assessment in a feasible, adaptive webbased testing system," IEEE Trans. Educ., vol. 48, no. 4, pp. 688-695, Nov. 2005.

[29] K. K. Bhagat, N. P. Subheesh, B. Bhattacharya, and C. Y. Chang, "The design and development of identification of students' misconceptions in individualized learning environment (iSMILE) system," Eurasia J. Math. Sci. Technol. Educ., vol. 13, no. 1, pp. 19-34, 2017. 